\title{
Review of the Textbook Neurochemistry by A.A. Boldyrev, N.D. Eshchenko, V.A. Ilyukha, and E.I. Kaivarainen (Moscow: Drofa, 2010)
}

\author{
M. L. Kukushkin \\ Received May 5, 2010
}

DOI: $10.1134 / \mathrm{S} 1819712410040100$

In 2010, the Drofa publishing house issued a book that was needed in our higher education institutions, namely, a "Neurochemistry" textbook. This textbook for higher education students was written by a collective of authors who teach courses in neurochemistry at Moscow State University (A.A. Boldyrev), St. Petersburg University (N.D. Eshchenko), and Petrozavodsk State University (V.A. Ilyukha and E.I. Kaivarainen). I do not know how the authors wrote this book, whether the four wrote it during meetings, or if chapters were divided between the authors and each author wrote his text and reviewed the text written by the other coauthors. In either case, the quartet was cohesive and they created an integral modern book united by one well-defined subject.

The textbook has three sections, viz., "structure of nervous tissue," "molecular neurochemistry," and "functional neurochemistry." Each section has modern, informative illustrations and the majority of the illustrations are original. Portraits of many of the scientists whose data are presented are shown in the textbook. This provides an excellent opportunity for students to "look into the eyes" of the researchers who contributed to the development of this science.

I would like to stress two specific features of the textbook. First, it is a very good classic text that includes the bases of neurochemistry and also reflects the development of modern neurochemical views. This makes this book not only a textbook on a given discipline, but also an aid that shows the path of scientific learning in this field. Second, the authors managed to condense the modern bases of this science into a relatively small volume (400 pages). Thus, they have successfully created the textbook that I.P. Ashmarin wanted to write several times (when he published selected chapters of his planned text) but unfortu- nately did not have enough time to finish. The authors' teachers were the founders of modern scientific schools: A.A. Boldyrev was a student of Academician S.E. Severin; N.D. Eshchenko was a student of Academician I.P. Ashmarin; and V.A. Ilyukha and E.I. Kaivarainen were students of the corresponding member of the Russian Academy of Sciences N.N. Nemova, who works actively in the field of ecological biochemistry.

Another merit of the book is the sympathetic attitude of the authors to the readers; while the book contains many abbreviations that frequently appear in modern natural sciences, an extensive list of abbreviations and a detailed subject index is included, which makes the book a useful handbook.

This book is beautifully formatted thanks to the efforts of both the authors and the editorial staff.

The referees (Prof. N.V. Gulyaeva and Prof. V.A.Golichenkov) and the scientific editor, Academician of the Russian Academy of Medical Sciences Yu.A. Vladimirov also certainly contributed to the structure of the textbook.

I believe that the only considerable drawback is the low quality of the paper. The publication of some part of the edition in a better format would not make this book more expensive, but would increase the lifespan of this useful textbook.

In general, the publication of this book, which is necessary for our higher education students, may be considered as timely. It should positively influence the general biological education of students in both biochemical and other related specialties (pharmacology, physiology, neurology, psychology, etc.). This is why this textbook was chosen by the learning-methodical association on classical university education. 